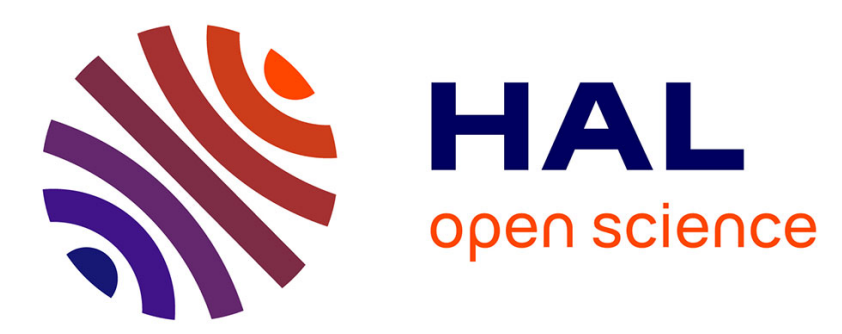

\title{
A Convergent, Stereoselective Route to Trisubstituted Alkenyl Boronates
}

\author{
Jean Michalland, Samir Zard
}

\section{To cite this version:}

Jean Michalland, Samir Zard. A Convergent, Stereoselective Route to Trisubstituted Alkenyl Boronates. Organic Letters, 2021, 23 (20), pp.8018-8022. 10.1021/acs.orglett.1c03022 . hal03416821

\section{HAL Id: hal-03416821 \\ https://hal.science/hal-03416821}

Submitted on 5 Nov 2021

HAL is a multi-disciplinary open access archive for the deposit and dissemination of scientific research documents, whether they are published or not. The documents may come from teaching and research institutions in France or abroad, or from public or private research centers.
L'archive ouverte pluridisciplinaire HAL, est destinée au dépôt et à la diffusion de documents scientifiques de niveau recherche, publiés ou non, émanant des établissements d'enseignement et de recherche français ou étrangers, des laboratoires publics ou privés. 
This document is confidential and is proprietary to the American Chemical Society and its authors. Do not copy or disclose without written permission. If you have received this item in error, notify the sender and delete all copies.

\section{A Convergent, Stereoselective Route to Trisubstituted Alkenyl Boronates}

\begin{tabular}{|c|c|}
\hline Journal: & Organic Letters \\
\hline Manuscript ID & Draft \\
\hline Manuscript Type: & Communication \\
\hline $\begin{array}{r}\text { Date Submitted by the } \\
\text { Author: }\end{array}$ & $n / a$ \\
\hline Complete List of Authors: & $\begin{array}{l}\text { Michalland, Jean; Ecole Polytechnique, Chemistry } \\
\text { Zard, Samir; Ecole Polytechnique, Chemistry }\end{array}$ \\
\hline
\end{tabular}

\section{SCHOLARONE \\ Manuscripts}




\section{A Convergent, Stereoselective Route to Trisubstituted Alkenyl Boronates}

Jean Michalland* and Samir Z. Zard*

Laboratoire de Synthèse Organique, CNRS UMR 7652, Ecole Polytechnique, 91128 Palaiseau Cedex, France Supporting Information Placeholder

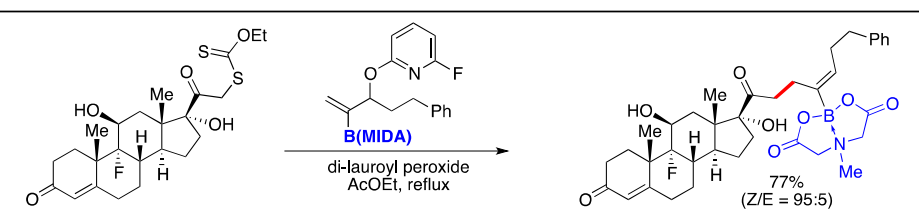

ABSTRACT: A modular, stereoselective route to trisubstituted (Z)-alkenyl (MIDA)boronates is described, consisting in the radical addition-fragmentation of dithiocarbonates to 2-(MIDA)boronyl-3-(2'-fluoro-pyridyl-6'-oxy)-alkenes. The bulky (MIDA)boronate ensures a highly stereoselective fragmentation that is enhanced by the poor stabilization of the radical adjacent to the tetravalent boron atom. The vinyl boronate precursors are prepared from propargyl alcohols by copper-catalyzed regioselective hydroborylation of their fluoropyridoxy derivatives, with the fluoropyridine acting as an internal directing group.

The importance of organoboron compounds to organic synthesis, medicinal chemistry, and material sciences is overwhelming. ${ }^{1}$ Indeed, the Suzuki-Miyaura cross-coupling ranks in the top five reactions used by medicinal chemists in drug discovery and development.2 The stability, low toxicity, and versatile reactivity of organoboronates are considerable advantages that make them almost ideal synthetic intermediates.

As partners in the Suzuki-Miyaura cross-coupling, alkenyl boronates occupy a particularly important position within the larger family of organoborons. The main routes to these substances are outlined in Scheme $1 .^{3}$ The Miyaura palladium-catalyzed coupling of alkenyl halides or triflates with organodiboron reagents $(\mathrm{A}){ }_{1}^{4}$ including the recent variation consisting in generating the palladium complex from a tosylhydrazone (B), ${ }^{4 b}$ as well as the boron-Heck ( $A, X$ $=H)_{i}^{5}$ the direct borylation of alkenyllithiums $(C)^{6}$ and the hydroboration (and carboboration) of alkynes (D,E), constitute the most common approaches. Other less employed methods include bora-Wittig condensation of gem-bis-boronates with aldehydes and ketones $(F), 8$ rhodium catalyzed conjugate addition of gem-bis-boraalkenes and gem-borazirconocenes to enones, ${ }^{9}$ and the cross-metathesis between an alkenyl boronate and an alkene $(\mathrm{G}) .{ }^{10}$ As with all chemical reactions, each of these routes has its drawbacks. In some instances, it is the limited availability of the substrates; in others, it is the incompatibility with the presence of polar groups, as is the case with reactions involving alkenyllithiums; or, as in the hydroborylation of unsymmetrical internal alkynes, the problem can be a low regioselectivity.

Scheme 1. Main Routes to Alkenyl Boronates

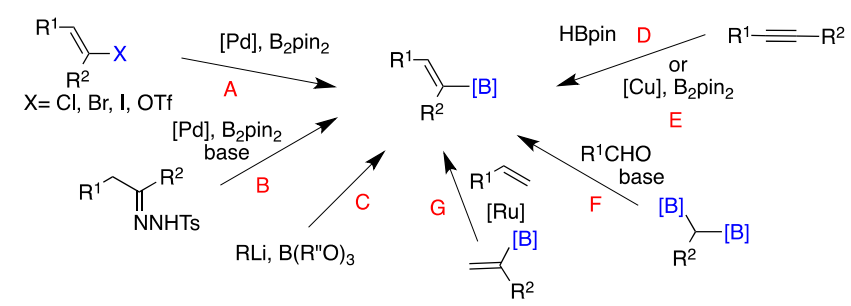

Radical processes have seldom been applied to the synthesis of alkenyl boronates..$^{11}$ As part of our work on the unusual radical chemistry of dithiocarbonates (xanthates), ${ }_{1}^{12}$ we decided to exploit an earlier observation to develop a convergent, stereoselective approach to these important derivatives. One feature of radical intermediates is that $\beta$ scission by homolysis of carbon-oxygen bonds $(1 \rightarrow 2$, Scheme 2) is generally a difficult process (i. e. very slow on radical reactions timescale) that is not normally observed. ${ }^{13}$ This is in stark contrast to the heterolytic $\beta$-elimination $(3 \rightarrow$ 
2) that is often encountered in ionic and organometallic chemistry. The lack of $\beta$-scission in the case of radical intermediates is a considerable synthetic asset when working with carbohydrates and terpenes, among others, where carbon-oxygen bonds are found in abundance. ${ }^{14}$ However, the ability of forcing the homolytic $\beta$-scission of a carbonoxygen bond opens up numerous synthetic opportunities not hitherto available. We discovered that the fluoropyridoxy group, in conjunction with the relative long lifetime of radicals generated from xanthates, can indeed undergo the homolytic $\beta$-scission $(10 \rightarrow 12$, Scheme 2$){ }^{15}$ This alliance translates into a powerful synthesis of alkenes, as outlined in the lower part of Scheme $2(9 \rightarrow 12) .{ }^{16}$

\section{Scheme 2. Formation of Alkenes}

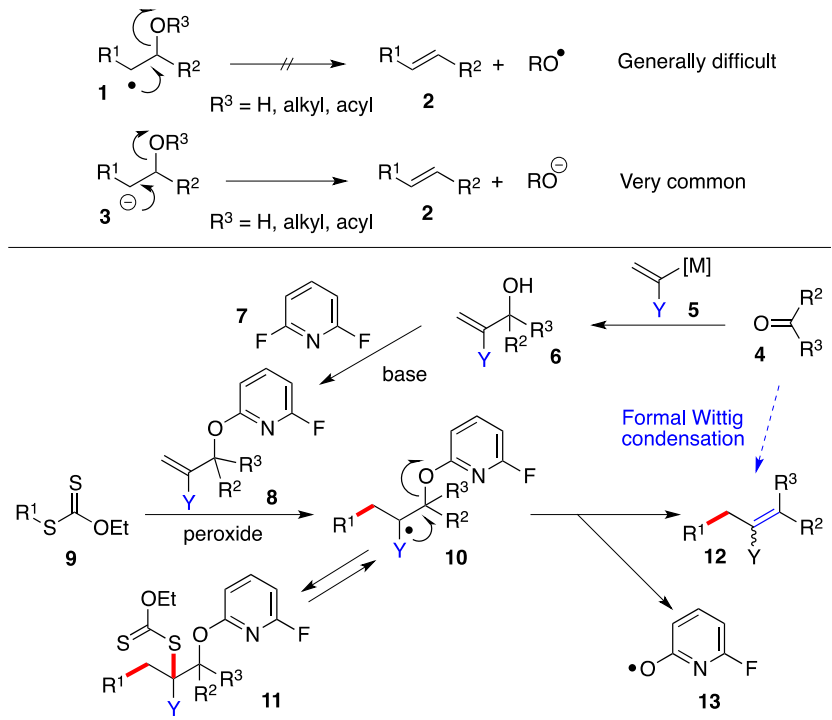

By converting an allylic alcohol 6 into its fluoropyridoxy derivative 8 and taking advantage of the ability of xanthates 9 to mediate intermolecular additions even to electronically unbiased alkenes, an addition-fragmentation sequence can be accomplished to furnish alkene 12 . The $\beta$-scission of intermediate radical 10 is in most cases slower than transfer of the xanthate group to give xanthate 11 , but this is of no consequence since this transfer is reversible. ${ }^{12}$ Radical 10 is continuously regenerated and ultimately collapses into the desired alkene 12. Many functional groups are tolerated, both on xanthate 9 and on activated allylic alcohol 8, allowing the synthesis of alkenes with numerous combinations of substituents and functionalities. One interesting observation is that, while the starting allylic alcohols 6 can be obtained by various methods, one of the main routes is by reaction of a vinylmetal 5 with a ketone or aldehyde 4 . The overall sequence would thus correspond to a formal equivalent of a Wittig condensation ( $4 \rightarrow 12$, Scheme 2 ).

To extend this strategy to the synthesis of alkenyl boronates, it is necessary to devise a route to the requisite precursors $8, Y=[B]$. We initially contemplated the obtention of the borylated allylic alcohols $6, Y=$ pinacolato boronate (Bpin), by addition of the corresponding vinyllithium reagent $5, Y=[B p i n]$ and $[\mathrm{M}]=\mathrm{Li}$, to an aldehyde; however, the 1bromovinylBpin precursor is tedious and expensive to make. ${ }^{17}$ We therefore explored the route proceeding by hydroboration of propargyl alcohols, inspired by earlier work by the groups of Hoveyda ${ }^{18}$ and Carretero ${ }^{19}$ on the regioselective reductive borylation of alkynes directed by substituents on the propargylic position. Using conditions developed by Carretero, ${ }^{19 a}$ we succeeded in converting propargyl alcohol 14a into vinyl pinacolato boronate 15 in good yield (Scheme 3). Unfortunately, its transformation into the desired precursor $16 \mathrm{a}$ by reaction of the corresponding alcoholate with 2,6-difluoropyridine 7 proceeded poorly. The reaction was very slow, with only around $11 \%$ of product being formed after 3 days (by NMR).

\section{Scheme 3. Synthesis of Precursors 16}

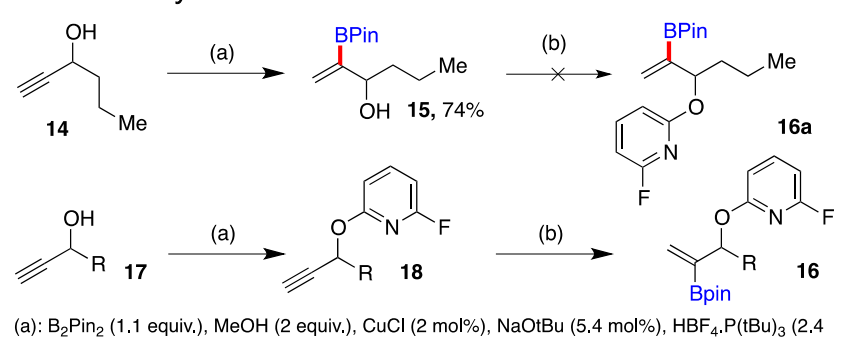
mol\%), toluene, rt; (b): $\mathrm{NaH}$ (1.2equiv.), DMSO, rt; 2,6-difluoropyridine 7
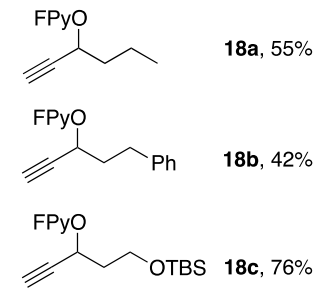

$\mathrm{CMe}_{3} \quad \mathbf{1 8 d}, 79 \%$

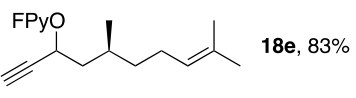

V $18 \mathrm{f}, 61 \%$

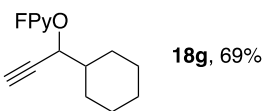

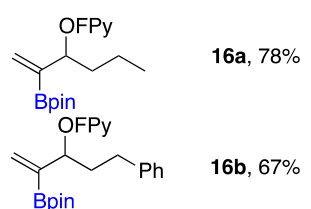
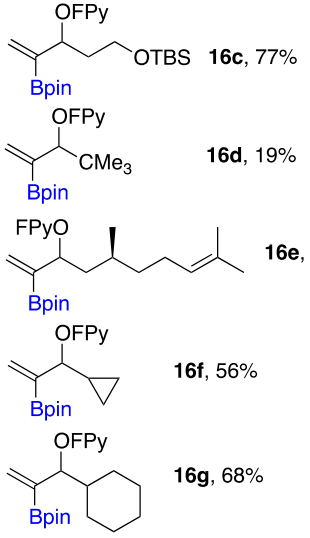

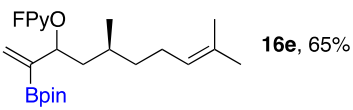

Following this setback, we reversed the order of the steps. The Carretero group previously used a propargylic 2pyridylsufonyl group to direct the borylation of the alkyne, ${ }^{19 a}$ so it seemed reasonable to expect a similar directing behavior from the fluoropyridoxy motif. Our radical "leaving group" would thus also act as a directing group for the regioselective borylation of the adjacent alkyne. To test this modified route, 
a series of propargylic alcohols 17a-g were converted into the corresponding fluoropyridoxy derivatives $18 \mathrm{a}-\mathrm{g}$ by reaction of the alcoholates with 2,6-difluoropyridine Exposure to $\mathrm{B}_{2} \mathrm{Pin}_{2}$ under the cuprous chloride catalysis conditions specified by Carretero et al. ${ }^{19 a}$ furnished indeed the long-sought derivatives $19 a-g$ in generally good yield, except for the $t$-butyl derivative $19 \mathrm{~d}$ which reacted poorly, presumably because of steric hindrance. In this case, the reaction did not go to completion, with $40 \%$ of starting material being isolated (yield based on recovered starting material is therefore $~ 30 \%)$. Furthermore, unlike the other alkynes where the regioselectivity was greater than 9:1 in favor of internal boronate, the regioselectivity of the hydroborylation of 18d was only 3:2 (see SI for details).

With the requisite activated allylic alcohols in hand, we could now examine the formation of alkenyl boronates by the addition-fragmentation process. Compound 16a was thus treated with two xanthates $9 \mathrm{a}$ and $9 \mathrm{~b}$, precursors to radicals of different stabilities and polar characteristics (Scheme 4). The reactions were conducted in refluxing ethyl acetate with portion-wise addition of stoichiometric amounts of di-lauroyl peroxide (DLP, also sold under lauroyl peroxide, Laurox ${ }^{\circledR}$ or Luperox $($ ). It is necessary to use the peroxide in stoichiometric quantities because the fluoropyridoxyl radical 13, generated in the fragmentation step (Scheme 2), does not propagate the chain.

\section{Scheme 4. Synthesis of Alkenyl Pinacolato Boronates}

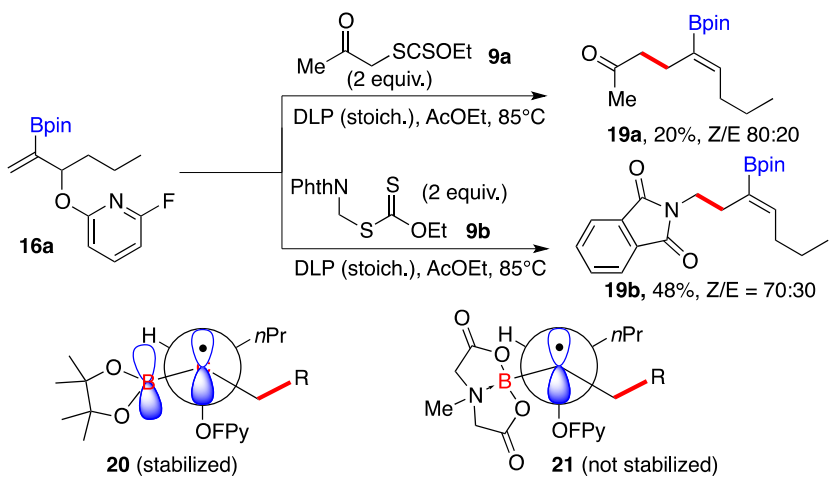

The desired reaction to give the corresponding alkenyl boronates 19a and 19b did indeed take place; unfortunately, the yield was modest and the stereoselectivity, while good, was below the level deemed synthetically useful. From previous experience with radical additions to vinyl boronates, ${ }^{20}$ we surmised that the problematic step was the fragmentation, which was too slow because of the stabilization of the intermediate adduct radical 20 by spin delocalization into the empty orbital of the trivalent boron atom. ${ }^{21}$

As for the stereoselectivity, the pinacolato boronate group is clearly not sufficiently bulky to exert total control over the fragmentation. ${ }^{22}$ The most favorable conformation corresponds to structure 20 , where the orbital containing the unpaired electron (the SOMO) is in the same plane as the CO bond linking the fluoropyridoxy group, with the boronate located anti to the propyl. Fragmentation then furnishes the $Z$ geometric isomer as the major product. To solve both problems of slow fragmentation and insufficient stereoselectivity, we decided to replace the pinacolato boronate with the bulkier MIDA boronate. The corresponding adduct radical 21 is less stabilized because the boron atom is now tetravalent with no vacant orbital available for delocalization, ${ }^{20 c}$ and the significantly increased steric bulk should improve the stereoselectivity by favoring more strongly conformation 21 pictured in Scheme 4 and leading to the cis isomer.

We initially attempted to access the desired MIDA boronate substrates by starting with 1-bromovinyl MIDA boronate which, unlike 1-bromovinylBpin, is easy to make and even commercially available. ${ }^{23}$ After some effort, we found that it is possible to couple it with hydrocinnamaldehyde under typical Nozaki-Hiyama-Kishi conditions; however, our attempts to introduce the fluoropyridyl group on the resulting alcohol 22 failed to give the desired derivative 23a (Scheme 5). We therefore resorted to another route, namely converting vinyl pinacolato boronates $19 \mathrm{a}-\mathrm{g}$ into the corresponding vinyl MIDA boronates 23a-g. We employed two methods, as shown in Scheme $5 .{ }^{24}$ In method $\mathrm{A}$, the boronic acid is formed by cleaving the pinacol motif with periodate and then converted into the MIDA boronate by treatment with $\mathrm{N}$-methyl iminodiacetic acid (MIDA). ${ }^{24 a}$ In the second, method B, the pinacolato boronate is heated with MIDA and triethyl orthoformate in DMSO at $100{ }^{\circ} \mathrm{C}$ for three days. Even though slow, this method is nevertheless equally convenient for substrates that do not contain fragile functionality. ${ }^{24 b}$

Scheme 5. Synthesis of Alkenyl Pinacolato Boronates

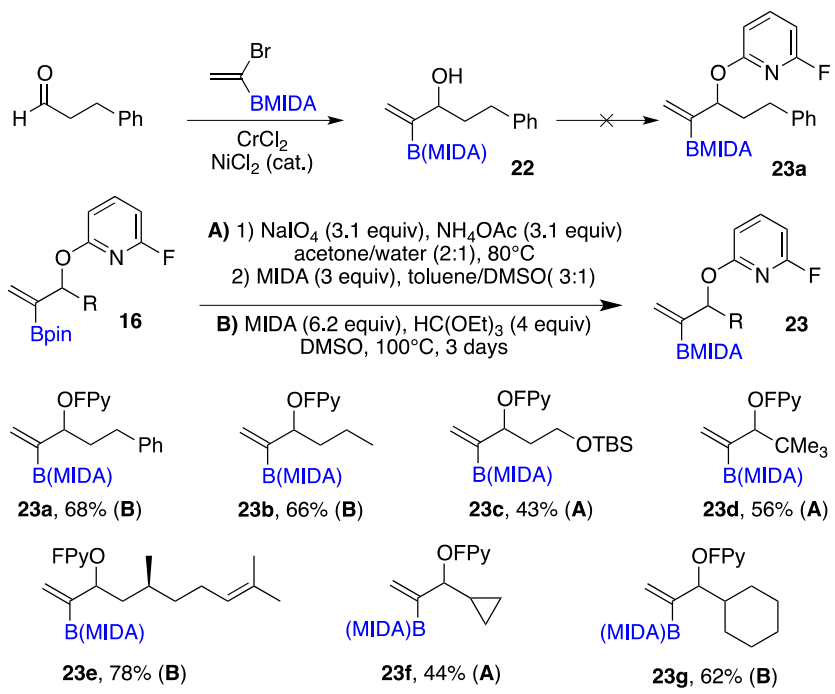


Our expectations were borne out in practice. Thus, addition of various xanthates to the fluoropyridoxy derivatized vinyl MIDA boronates 23a-g furnished products 24a-p (Scheme 6). The yields are generally good and the stereoselectivity is in most cases $\geq 95: 5$ in favor of the desired $Z$ isomer, as determined by NMR spectroscopy. The two notable exceptions, $23 \mathrm{~d}$ and $23 \mathrm{e}$, involve tertiary xanthates. The yield was disappointingly low and, for the latter, the stereoselectivity was also poor, presumably because the tertiary group introduced is also quite bulky. Further work is needed to better understand the source of difficulty in such cases.

At any rate, trisubstituted alkenyl boronates with defined geometry and bearing a variety of functional groups can be readily prepared. In particular, the compatibility with polar functionalities, such as ketones, lactones, imides, amides, including Weinreb amides, free hydroxy groups, and fluorinated motifs, are a hallmark of radical processes and a unique synthetic asset. Indeed, many of the compounds displayed in Scheme 6 would be accessible only tediously by any of the established routes summarized in Scheme 1 . The formation of corticosteroid boronate $24 p$, without the need for any prior protection, illustrates nicely the broad functional group tolerance.

\section{Scheme 6 . Synthesis of Alkenyl MIDA Boronates}

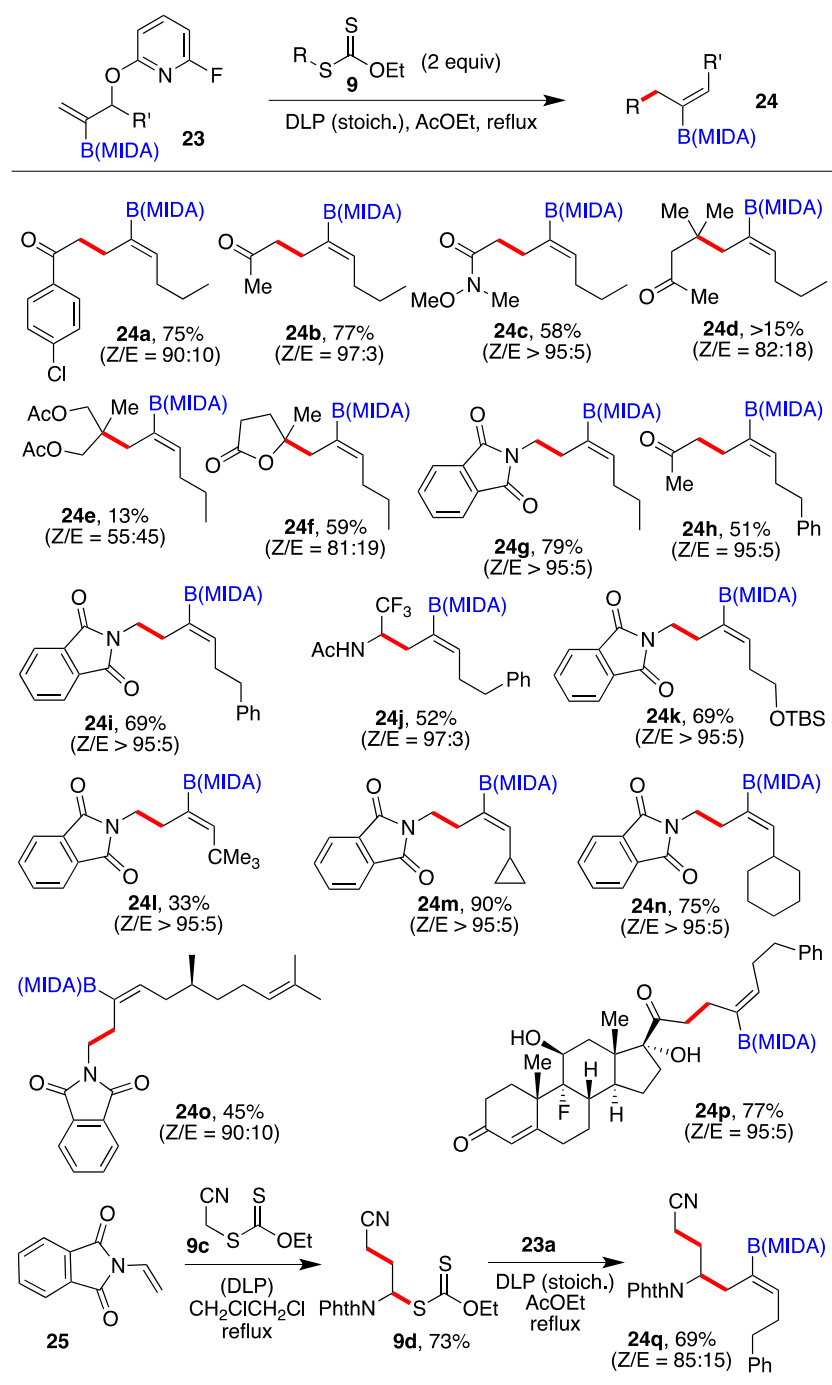

Increase in complexity can be achieved by taking advantage of another property of the xanthate-based technology, namely that the addition of a xanthate 9 to an alkene leads to another xanthate, which in turn can be converted into an alkenyl boronate by the chemistry described herein. This variation is exemplified by the sequence at the bottom of Scheme 6, whereby cyanomethyl xanthate $9 \mathrm{c}$ is added to $\mathrm{N}$-vinyl phthalimide 25 to provide a new xanthate $9 d_{1}{ }^{25}$ which is then made to react with alkene 23a to give alkenyl boronate 24q. The first step is a true radical chain, requiring sub-stoichiometric amounts of the peroxide initiator. In this manner, three different molecules have been combined and two new C-C bonds created in an intermolecular fashion. Different functional groups can be present on each partner allowing for numerous combinations in principle.

To summarize, we have developed a modular, versatile, and highly stereoselective route to alkenyl MIDA boronates. I is tolerant of many of the functional groups encountered in modern synthesis and is easily scalable. Thus, alkenyl 
boronate 24a could be prepared on $1.4 \mathrm{~g}$ scale without loss of efficacy. Indeed, the yield was slightly higher (81\% vs 75\%) and the stereoselectivity remained the same (90:10). The stereoselectivity could in principle be further increased by the use of substituents on the boron that are bulkier than MIDA, as for example the pinene derived iminodiacetic (PIDA), which has the further advantage of allowing subsequent diastereoselective transformations of the resulting alkenyl boronate. 26

MIDA boronates offer many advantages as compared to the popular pinacolato boronates. ${ }^{27}$ They are more robust, more stable towards chromatographic purification, can be precipitated by dilution with a non-polar solvent such as ether, and are much less subject to protodeborylation. They can nevertheless be converted into the free boronic acid or other boronates, if so desired.28 This is illustrated by the straightforward conversion of boronate $24 a$ into pinacolato boronate 19c depicted in Scheme 7. This indirect route to alkenyl pinacolato boronates 19 circumvents the shortcomings of the initial approach discussed in Scheme 3. Another useful transformation is of course the SuzukiMiyaura cross-coupling, in this case with $p$-iodoanisole to give 26 with essentially no erosion of the stereochemical integrity. ${ }^{27 c}$ Finally, ozonolysis of the alkene, as described by Bode, Ito and co-workers, ${ }^{24 b}$ furnishes acyl boronate 27. Acyl boronates are relatively rare substances that are emerging as quite useful synthetic intermediates. 29

\section{Scheme 7. Examples of Post-Modifications of an Alkenyl} MIDA Boronate

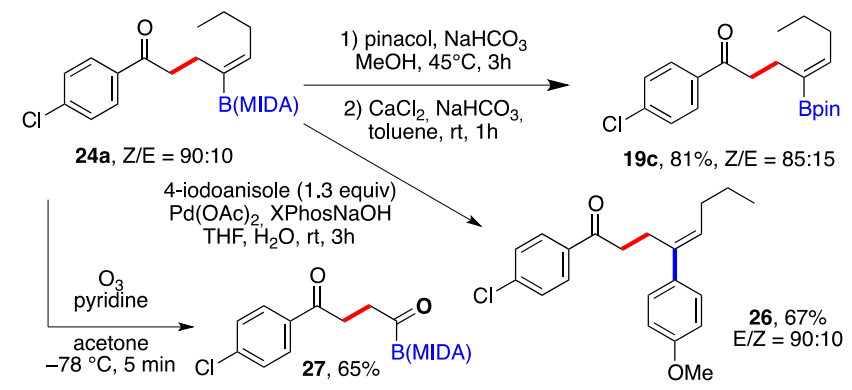

\section{ASSOCIATED CONTENT}

\section{Supporting Information}

Experimental procedures, full spectroscopic data, and copies of $1 \mathrm{H}$ and $13 \mathrm{C}$ NMR for all new compounds. This material is available free of charge via the Internet at http://pubs.acs.org.

\section{AUTHOR INFORMATION}

\section{Corresponding Author}

samir.zard@polytechnique.edu jean.michalland@polytechnique.edu

\section{ACKNOWLEDGMENTS}

We thank Ecole Polytechnique for a scholarship to J. M., and Mrs Sophie Bourcier and Mr Vincent Jactel (both at Ecole Polytechnique) for HRMS measurements.

\section{DEDICATION}

This article is affectionately dedicated to Professor Troels Skrysdrup (Aarhus University) on the occasion of his $60^{\text {th }}$ birthday.

\section{REFERENCES}

(1) Selected monographs and books: (a) Hall, D. G., Ed. Boronic Acids: Preparation and Applications in Organic Synthesis, Medicine and Materials, Vols. 1 and 2; Wiley-VCH: New York, 2011. (b) Fyfe, J. W. B.; Watson, A. J. B. Recent Developments in Organoboron Chemistry: Old Dogs, New Tricks. Chem 2017, 3, 31-55.

(2) (a) Miyaura, N.; Suzuki, A. Palladium-Catalyzed Cross-Coupling Reactions of Organoboron Compounds. Chem. Rev. 1995, 95, 24572483. (b) Koshvandi, A. T. K.; Heravi, M. M.; Momeni, T. Current Applications of Suzuki-Miyaura Coupling Reaction in the Total Synthesis of Natural Products: An Update. Appl. Organomet. Chem. 2018, 32, e4210. (c) Brown, D. G.; Boström, J. Analysis of Past and Present Synthetic Methodologies on Medicinal Chemistry: Where Have All the New Reactions Gone?: Miniperspective. J. Med. Chem. 2016, 59, 4443-4458.

(3) For a recent review, see: Carreras, J.; Caballero, A.; Pérez, P. J. Alkenyl Boronates: Synthesis and Applications. Chem. Asian J. 2019, 14, 329-343.

(4) (a) Takagi, J.; Takahashi, K.; Ishiyama, T.; Miyaura, N. PalladiumCatalyzed Cross-Coupling Reaction of Bis(Pinacolato)Diboron with 1-Alkenyl Halides or Triflates: Convenient Synthesis of Unsymmetrical 1,3-Dienes via the Borylation-Coupling Sequence. J. Am. Chem. Soc. 2002, 124, 8001-8006. (b) Ping, Y.; Wang, R.; Wang, Q.; Chang, T.; Huo, J.; Lei, M.; Wang, J. Synthesis of Alkenylboronates from N-Tosylhydrazones through Palladium-Catalyzed Carbene Migratory Insertion. J. Am. Chem. Soc. 2021, 143, 9769-9780.

(5) (a) Idowu, O. O.; Hayes, J. C.; Reid, W. B.; Watson, D. A. Synthesis of 1,1-Diboryl Alkenes Using the Boryl-Heck Reaction. Org. Lett. 2021, 23, 4838-4842. (b) Reid, W. B.; Watson, D. A. Synthesis of Trisubstituted Alkenyl Boronic Esters from Alkenes Using the BorylHeck Reaction. Org. Lett. 2018, 20, 6832-6835.

(6) Brown, H. C.; Bhat, N. G. A Simple Conversion of $[\mathrm{E}]-$ into the Isomeric [Z]-2-(1-Substituted-1-Alkenyl)-1,3,2-Dioxaborinanes, Providing a Convenient Stereospecific Synthesis of Both [E]- and [Z]1,2-Disubstituted Vinyl Bromides. Tet. Lett. 1988, 29, 21-24.

(7) (a) Liu, X.; Ming, W.; Friedrich, A.; Kerner, F.; Marder, T. B. CopperCatalyzed Triboration of Terminal Alkynes Using B2pin2: Efficient Synthesis of 1,1,2-Triborylalkenes. Angew. Chem. Int. Ed. 2020, 59, 304-309. (b) Itoh, T.; Shimizu, Y.; Kanai, M. Ligand-Enabled, CopperCatalyzed Regio- and Stereoselective Synthesis of Trialkylsubstituted Alkenylboronates from Unactivated Internal Alkynes. J. Am. Chem. Soc. 2016, 138, 7528-7531. (c) Alfaro, R.; Parra, A.; Alemán, J.; García Ruano, J. L.; Tortosa, M. Copper(I)-Catalyzed Formal Carboboration of Alkynes: Synthesis of Tri- and Tetrasubstituted Vinylboronates. J. Am. Chem. Soc. 2012, 134, 15165-15168. (d) For a review, see: (i) Yoshida, H. Borylation of Alkynes under Base/Coinage Metal Catalysis: Some Recent Developments. ACS Catal. 2016, 6, 17991811. 
(8) (a) Namirembe, S.; Gao, C.; Wexler, R. P.; Morken, J. P. Stereoselective Synthesis of Trisubstituted Alkenylboron Reagents by Boron-Wittig Reaction of Ketones. Org. Lett. 2019, 21, 4392-4394. For a review, see: (b) Cuenca, A. B.; Fernández, E. Boron-Wittig Olefination with Gem-Bis(Boryl)Alkanes. Chem. Soc. Rev. 2021, 50, $72-86$.

(9) (a) Liang, M. Z.; Meek, S. J. Catalytic Enantioselective Synthesis of 1,4-Keto-Alkenylboronate Esters and 1,4-Dicarbonyls. Angew. Chem. Int. Ed. 2019, 58, 14234-14239. (b) Deloux, L.; SkrzypczakJankun, E.; Cheesman, B. V.; Srebnik, M.; Sabat, M. First Example of Stable 1,1-Bimetalloalkenes of Boron and Zirconium: Synthesis, Reactivity, X-Ray Analysis, and NMR Studies. J. Am. Chem. Soc. 1994, 116, 10302-10303.

(10) Morrill, C.; Funk, T. W.; Grubbs, R. H. Synthesis of Tri-Substituted Vinyl Boronates via Ruthenium-Catalyzed Olefin Cross-Metathesis. Tet. Lett. 2004, 45, 7733-7736.

(11) (a) Barzanò, G.; Cheseaux, A.; Hu, X. Z-Selective Synthesis of Vinyl Boronates through Fe-Catalyzed Alkyl Radical Addition. Org. Lett. 2019, 21, 490-493. One example of a radical addition / ring opening of ethyl difluoroiodoacetate to cyclopropyl vinyl boronate to give a vinyl boronate has been recently reported, but no stereoselectivity was observed. See: (b) Fang, T.; Qiu, J.; Yang, K.; Song, Q. Photo-Induced Weak Base-Catalyzed Synthesis of $\alpha$ Haloboronates from Vinylboronates and Polyfluoroalkyl Halides. Org. Chem. Front. 2021, 8, 1991-1996.

(12) Zard, S. Z. Radical Alliances: Solutions and Opportunities for Organic Synthesis. Helv. Chim. Acta 2019, 102, e1900134.

(13) Crich, D.; Brebion, F.; Suk, D.-H. Generation of Alkene Radical Cations by Heterolysis of $\beta$-Substituted Radicals: Mechanism, Stereochemistry, and Applications in Synthesis. Top. Curr. Chem. 2006, 263, 1-38.

(14) Renaud, P.; Sibi, M. P. Eds. Radicals in Organic Synthesis, Vols. 1 and 2; Wiley- VCH: Weinheim, Germany, 2001.

(15) Charrier, N.; Quiclet-Sire, B.; Zard, S. Z. Allylic Alcohols as Radical Allylating Agents. An Overall Olefination of Aldehydes and Ketones. J. Am. Chem. Soc. 2008, 130, 8898-8899.

(16) Debien, L.; Quiclet-Sire, B.; Zard, S. Z. Allylic Alcohols: Ideal Radical Allylating Agents? Acc. Chem. Res. 2015, 48, 1237-1253.

(17) Roseblade, S. J.; Smilović, I. G.; Časar, Z. Study of Chemoselective Asymmetric Hydrogenation of (1-Bromo-1-Alkenyl)Boronic Esters with Iridium-P^N Complexes. Tetrahedron 2014, 70, 2654-2660.

(18) Jang, H.; Zhugralin, A. R.; Lee, Y.; Hoveyda, A. H. Highly Selective Methods for Synthesis of Internal $(\alpha-)$ Vinylboronates through Efficient NHC-Cu-Catalyzed Hydroboration of Terminal Alkynes. Utility in Chemical Synthesis and Mechanistic Basis for Selectivity. J. Am. Chem. Soc. 2011, 133, 7859-7871.

(19) (a) Moure, A. L.; Mauleón, P.; Gómez Arrayás, R.; Carretero, J. C. Formal Regiocontrolled Hydroboration of Unbiased Internal Alkynes via Borylation/Allylic Alkylation of Terminal Alkynes. Org. Lett. 2013, 15, 2054-2057. (b) Moure, A. L.; Gómez Arrayás, R.; Cárdenas, D. J.; Alonso, I.; Carretero, J. C. Regiocontrolled Cu ${ }^{\text {I }}$-Catalyzed Borylation of Propargylic-Functionalized Internal Alkynes. J. Am. Chem. Soc. 2012, 134, 7219-7222.

(20) (a) Huang, Q.; Michalland, J.; Zard, S. Z. Alternating Radical Stabilities: A Convergent Route to Terminal and Internal Boronates. Angew. Chem. Int. Ed. 2019, 58, 16936-16942. (b) Huang, Q.; Zard, S. Z. Radical Fragment Coupling Route to Geminal Bis(Boronates). Org. Lett. 2018, 20, 5304-5308. (c) Quiclet-Sire, B.; Zard, S. Z. Radical
Instability in Aid of Efficiency: A Powerful Route to Highly Functional MIDA Boronates. J. Am. Chem. Soc. 2015, 137, 6762-6765.

(21) The calculated radical stabilization energy (RSE) for borylmethyl radical $\mathrm{H}_{2} \mathrm{BCH}_{2}$ is $10-11 \mathrm{kcal} / \mathrm{mol}$, a value only slightly lower than that of a benzyl radical (RSE $=14-15 \mathrm{kcal} / \mathrm{mol})$. This stabilization is slightly reduced to about 6-7 $\mathrm{kcal} / \mathrm{mol}$ with oxygen substitutents. See: (a) Henry, D. J.; Parkinson, C. J.; Mayer, P. M.; Radom, L. Bond Dissociation Energies and Radical Stabilization Energies Associated with Substituted Methyl Radicals. J. Phys. Chem. A 2001, 105, 67506756. (b) Walton, J. C.; McCarroll, A. J.; Chen, Q.; Carboni, B.; Nziengui, R. The Influence of Boryl Substituents on the Formation and Reactivity of Adjacent and Vicinal Free Radical Centers. J. Am. Chem. Soc. 2000, 122, 5455-5463.

(22) Recent calculations by the Aggarwal group indicated that the A value for a pinacolato boronate is in fact significantly smaller than that of a methyl $(0.4 \mathrm{kcal} / \mathrm{mole} v \mathrm{vs} 1.7 \mathrm{kcal} / \mathrm{mol})$ : Fasano, $V_{\text {.; }}$ McFord, A. W.; Butts, C. P.; Collins, B. S. L.; Fey, N.; Alder, R. W.; Aggarwal, V. K. How Big Is the Pinacol Boronic Ester as a Substituent? Angew. Chem. Int. Ed. 2020, 59, 22403-22407.

(23) Woerly, E. M.; Miller, J. E.; Burke, M. D. (1-Bromovinyl)-MIDA Boronate: A Readily Accessible and Highly Versatile Building Block for Small Molecule Synthesis. Tetrahedron 2013, 69, 7732-7740.

(24) (a) Lepage, M. L.; Lai, S.; Peressin, N.; Hadjerci, R.; Patrick, B. O.; Perrin, D. M. Direct Access to MIDA Acylboronates through Mild Oxidation of MIDA Vinylboronates. Angew. Chem. Int. Ed. 2017, 56, 15257-15261. (b) Taguchi, J.; Ikeda, T.; Takahashi, R.; Sasaki, I.; Ogasawara, Y.; Dairi, T.; Kato, N.; Yamamoto, Y.; Bode, J. W.; Ito, H. Synthesis of Acylborons by Ozonolysis of Alkenylboronates: Preparation of an Enantioenriched Amino Acid Acylboronate. Angew. Chem. Int. Ed. 2017, 56, 13847-13851.

(25) Quiclet-Sire, B.; Revol, G.; Zard, S. Z. A Convergent, Modular Approach to Complex Amines. Tetrahedron 2010, 66, 6656-6666.

(26) Li, J.; Burke, M. D. Pinene-Derived Iminodiacetic Acid (PIDA): A Powerful Ligand for Stereoselective Synthesis and Iterative CrossCoupling of $\mathrm{C}(\mathrm{Sp} 3)$ Boronate Building Blocks. J. Am. Chem. Soc. 2011, 133, 13774-13777.

(27) (a) Li, J.; Grillo, A. S.; Burke, M. D. From Synthesis to Function via Iterative Assembly of $\mathrm{N}$-Methyliminodiacetic Acid Boronate Building Blocks. Acc. Chem. Res. 2015, 48, 2297-2307. (b) He, Z.; Zajdlik, A.; Yudin, A. K. Air- and Moisture-Stable Amphoteric Molecules: Enabling Reagents in Synthesis. Acc. Chem. Res. 2014, 47, 10291040. (c) Haley, H. M. S.; Hill, A. G.; Greenwood, A. I.; Woerly, E. M.; Rienstra, C. M.; Burke, M. D. Peridinin Is an Exceptionally Potent and Membrane-Embedded Inhibitor of Bilayer Lipid Peroxidation. J. Am. Chem. Soc. 2018, 140, 15227-15240.

(28) (a) Wang, H.; Zeng, Y.-F.; LV, W.-X.; Tan, D.-H. Synthetic Transformations of Alkenyl MIDA Boronates toward the Efficient Construction of Organoborons. Synlett 2018, 29, 1415-1420. (b) Woerly, E. M.; Roy, J.; Burke, M. D. Synthesis of Most Polyene Natural Product Motifs Using Just 12 Building Blocks and One Coupling Reaction. Nature Chem. 2014, 6, 484-491.

(29) (a) Wu, D.; Taguchi, J.; Tanriver, M.; Bode, J. W. Synthesis of Acylboron Compounds. Angew. Chem. Int. Ed. 2020, 59, 1684716858. (b) Šterman, A.; Sosič, I.; Gobec, S.; Časar, Z. Recent Advances in the Synthesis of Acylboranes and Their Widening Applicability. ACS Omega 2020, 5, 17868-17875. (c) Scharnagl, F. K.; Bose, S. K.; Marder, T. B. Acylboranes: Synthetic Strategies and Applications. Org. Biomol. Chem. 2017, 15, 1738-1752. 